\title{
ESTRATÉGIA DE GRUPOS COMO DISPOSITIVO DE CUIDADO EM UM CENTRO DE ATENÇÃO PSICOSSOCIAL INFANTOJUVENIL
}

\author{
Mariéle Vargas Vieira1; Bibiana Massem Homercher²; Juliana Magrinni \\ Bernardi $^{3}$; Cristiane Wagner ${ }^{4}$
}

\section{RESUMO}

O presente trabalho foi construído e embasado através de um relato de experiência sob o olhar de profissionais de uma residência multiprofissional em um Centro de Atenção Psicossocial Infantojuvenil (CAPSi) na região centro do Rio Grande do Sul. Com o objetivo de desvelar os benefícios da terapia em grupo como possibilidades e estratégias em atendimentos para adolescentes de 14 a 17 anos, agrupados por idades aproximadas e temáticas de atividades de suas preferências. A equipe de profissionais era composta por residentes do Programa de Residência Multiprofissional em Saúde Mental, sendo uma terapeuta ocupacional, uma psicóloga e uma assistente social. O trabalho multiprofissional será abordado e discutido, assim como os desafios que surgem com ele, e pela sua relevância neste serviço, o qual podemos observar que este promove diferentes olhares e ações nas atividades grupais promovendo um espaço acolhedor e facilitador aos adolescentes que foram encaminhados para este potente dispositivo de cuidado.

Palavras-chave: Adolescência, Equipe Multiprofissional, Intervenção Grupal, Saúde Mental.

\section{Eixo Temático: Atenção Integral e Promoção à Saúde}

\section{INTRODUÇÃO}

Este artigo foi elaborado a partir de relatos de experiência de três residentes em Saúde Mental (terapeuta ocupacional, psicóloga e assistente social), inseridas em um CAPSi na região centro do Rio Grande do Sul. O trabalho em equipe

\footnotetext{
${ }^{1}$ Terapeuta Ocupacional Residente Multiprofissional em Saúde Mental da Universidade Franciscana (UFN).mariele1939@hotmail.com.

2 Psicóloga Residente Multiprofissional em Saúde Mental, Universidade Franciscana (UFN). bibianamh@hotmail.com.

${ }^{3}$ Assistente Social Residente Multiprofissional em Saúde Mental da Universidade Franciscana (UFN). juuhmagrini@hotmail.com.

4 Orientadora. Tutora da Residência Multiprofissional da Universidade Franciscana (UFN). cristiane.wagner@ufn.edu.br.
} 
multiprofissional na estratégia de cuidado e ferramenta utilizada foi o atendimento grupal para adolescentes redirecionados do acolhimento por preferências semelhantes de atividades do seu cotidiano.

Os serviços de saúde mental para crianças e adolescentes surgem a partir de 2002, com o objetivo de prestar assistência a este público seguindo os mesmos princípios dos outros CAPS, dando atenção especializada para estes indivíduos que sofrem de algum transtorno mental, casos graves e persistentes, tentando inserir este ao convívio social, promovendo e estimulando a integração da família neste processo de cuidado, disponibilizando um ambiente acolhedor e favorável para oferecer várias modalidades de tratamento terapêutico (BRASIL, 2004).

Para Menezes et al (2020, p.120), "a adolescência pode ser conceituada como um período de transição entre a infância e a vida adulta e geralmente é entendida como um período de saúde, pois é a fase da vida que o desenvolvimento atinge seu ápice quanto às capacidades físicas." E ainda um momento de transição e construção da sua individualidade, das mudanças corporais, das suas relações sociais no contexto em que vive, fatores que podem gerar sentimentos de confusão e ansiedade (PICCIN, et al., 2019). Portanto este trabalho tem como objetivo geral desvelar os benefícios da terapia em grupo com adolescentes em um Centro de Apoio Psicossocial infanto juvenil, e enfatizar a importância da equipe multidisciplinar neste dispositivo.

\section{MEDOTOLOGIA}

O recurso metodológico utilizado neste trabalho é caracterizado como um relato de experiência aliado com a revisão de literatura de natureza qualitativa, na perspectiva de revisão bibliográfica descritiva. Sobre a pesquisa ser de caráter qualitativo, Demo (2008), considera que este processo possa ser nomeado de "objetivação", tal denominação significa demonstrar aprimoramento deste método, se empoderando das técnicas e instrumentos, aproximando ao máximo do objeto descrito "da sua lógica interna", inserindo este em seu contexto relacionando com o conhecimento já existente na literatura nacional e internacional 
Ressalta-se então que o intuito deste trabalho é analisar, relatar, discutir e possibilitar reflexões importantes sobre a prática e o trabalho na dinâmica de grupos para adolescentes de 14 a 17 anos agrupados por critérios de idades aproximadas, assim como das práticas cotidianas de preferências em comum, evidenciando a importância do trabalho que foi realizado e idealizado por uma em equipe multidisciplinar.

Para Gil (2002), no que tange a pesquisa bibliográfica esta se configura com base em materiais já existentes na literatura, sendo a principal fonte de dados retirados principalmente de livros e artigos científicos. Neste modelo de pesquisa as evidências científicas consideram critérios que comprovam a veracidade da metodologia utilizada, e os resultados provém de estudos científicos e seus objetivos alcançados, através dos métodos que moveram a validade dos critérios (MINAYO; COSTA, 2018). As fontes dessa pesquisa qualitativa foram ampliadas pelas ofertas de materiais nas seguintes plataformas: livros, revistas científicas, Biblioteca Eletrônica Científica Online (SCIELO), artigos científicos que tratam desta temática.

\section{RESULTADOS E DISCUSSÕES}

\subsection{Sobre a Construção e Funcionamento de Grupos no CAPSi}

Os grupos são de suma importância nos serviços de saúde mental, por proporcionar aos usuários possibilidades de tratamento que vai além do medicamentoso. O interesse nessa prática e os benefícios que ela traz, surge para suprir as demandas do serviço e porque esta prática de grupos está entre as estratégias de cuidado ofertadas e inseridas nos planos terapêuticos desses indivíduos.

Benevides et al., (2010), destaca que as ações e metodologias desenvolvidas na prática terapêutica de grupos irá proporcionar não somente a reabilitação do indivíduo, mas estimular o vínculo com a equipe que o acolheu, a interação com outros integrantes, colocando-o como corresponsável pelo seu tratamento e instigando a gerar mudanças na sua saúde mental e isso torna essa assistência com mais efetividade. Esta abordagem no trabalho em saúde mental ocorre a priori para 
um melhor enfrentamento do sofrimento psíquico de uma maneira mais natural entrelaçadas com outras experiências de vida (HEBERLE; OLIVEIRA, 2016).

A experiência no trabalho em grupo como residente em saúde mental proporcionou aprendizados, manejo de situações inesperadas, além de muitas trocas afetivas entre todos os participantes. Para sua efetividade, a sua construção seguiu algumas regras para o seu funcionamento, a iniciar pela idade proposta, foram agrupados adolescentes com faixa etária aproximadas (14 a 17 anos), sendo dois do sexo masculino e uma do sexo feminino, logo após essa definição, fizemos a escolha por experiências e estilos de vida com perfis parecidos, e por não se tratar de adolescentes com vulnerabilidade social, visto que todos tinham moradia, estavam frequentando a escola e tinham o suporte da família.

Eram indivíduos com históricos de agressividade, depressão e transtorno obsessivo compulsivo, além de também estarem reclusos em suas casas pelo fato da pandemia da Covid-19 e com alta dependência em jogos de internet. A dinâmica de grupo está entre umas das principais atividades desenvolvidas nos CAPS, uma proposta de trabalho que visa ao indivíduo o estímulo de sua criatividade, bem como suas habilidades e suas potencialidades, também conhecidas como oficinas, e que são trabalhadas as diversas problemáticas da vida humana, representando parte do trabalho não medicamentoso (SCHRANK; OLSCHOWSKY, 2008)

Os temas abordados foram os mais diversos, que fossem de encontro com as demandas apresentadas. As dinâmicas de grupo foram de curta duração, em torno de 45 a 50 minutos, fazendo com que os integrantes se envolvessem através de técnicas específicas e com significados bem definidos. Os meninos gostavam de trazer seus desenhos, que, na maioria das vezes, tinham relação com jogos da internet, as músicas também tinham essa mesma direção.

Houve, também, um momento na cozinha do serviço que foi realizado o preparo de um brigadeiro, o que permitiu integrar os participantes nesta atividade, compartilhamento de estilos musicais, e ainda promover a adequação de comportamentos diferentes uns dos outros, o que ocasionou estranheza para alguns deles, mas algo que não repercutia negativamente na sua operacionalidade. Promovemos momentos de escuta de seus anseios e angústias, de empoderamento 
e protagonismo da fala, de reestruturação das suas rotinas prejudicadas pela pandemia, exploramos a criatividade e raciocínio a partir de jogos que tínhamos disponíveis no serviço e na internet.

\subsection{O Trabalho em Equipe Multidisciplinar}

A composição da equipe multiprofissional neste grupo de adolescentes foi permeada pelas demandas apresentadas e pelos vínculos já estabelecidos anteriormente, quando os acolhimentos desses indivíduos foram realizados por estes mesmos profissionais. Cada um deles lançava e discutia as possibilidades e ideias de atividades que seriam trabalhadas a partir das suas percepções de seu núcleo específico. No decorrer do funcionamento dos atendimentos grupais as questões trazidas nos diálogos dos adolescentes traziam momentos de reflexão da equipe posteriormente para novas abordagens.

Para Silva e Trad (2013), em seus estudos, apontam vantagens no trabalho em equipe, como a troca de experiências, o respeito ao trabalho e à opinião de outros profissionais. Muitas são as vantagens do trabalho em equipe multiprofissional, como a integração de diferentes conhecimentos técnicos e com suas especificidades, não podendo ser praticada isoladamente, proporcionando não apenas nos resultados do tratamento dos indivíduos, mas ainda, o modo de atuação dos profissionais envolvidos, como na divisão das tarefas, no planejamento das atividades e integração e colaboração entre as profissões (OTENIO et al, 2008).

A residência em saúde mental é por um viés multiprofissional, onde é compartilhado saberes de outras áreas da saúde, e neste grupo terapêutico nos fez compreender o saber do outro e vice e versa, nos levando para uma busca e aprimoramento dos nossos conhecimentos, mas acima de tudo levar possibilidades de novas perspectivas e qualidade de vida a esses adolescentes que estavam em acompanhamento no CAPSi.

\section{CONCLUSÃO}

Com esse estudo ficou evidenciado que a prática de atividades das dinâmicas de grupo foi uma estratégia importante adotada no tratamento do sofrimento mental 
desses adolescentes que estavam em acompanhamento no CAPSi, proporcionando outras formas de cuidar desses sujeitos que não fosse pela via medicamentosa. Ademais, na terapia em grupo se prioriza a construção da subjetividade, a adequação de comportamentos inapropriados, conhecimento interior das emoções e sentimentos, tornando esse sujeito como protagonista das suas mudanças e por seu tratamento.

Os profissionais da equipe multiprofissional atuaram como mediadores e facilitadores desse ambiente acolhedor e favorável para que as questões trazidas fossem tratadas com respeito e importância, para que as trocas de experiências oportunizassem alternativas e soluções e enfrentamento dos problemas referidos. Neste espaço permitiu-se a construção de novas amizades, sem prejulgamentos e estigmas, permitindo que eles se sentissem valorizados pelos demais, responsabilizando-os por suas mudanças de hábitos e percepções das problemáticas apresentadas.

Houve também o cuidado de organizar as atividades, bem como o interesse que mais as agradavam, mas por querer atender as demandas que eles traziam no dia do grupo, essas atividades poderiam sofrer alterações. Com esse estudo fica evidenciado o importante e necessário trabalho da equipe multiprofissional que prima pela excelência nessa estratégia de cuidado ofertados pelos CAPSi, em constância nos estudos e avaliações dos métodos e meios utilizados, objetivando qualificar mais essas ações, para que se alcançasse mais efetividade e melhores resultados no tratamento do sofrimento mental desses adolescentes.

\section{REFERÊNCIAS}

BENEVIDES, D. S. et al. Cuidado em saúde mental por meio de grupos terapêuticos de um hospital-dia: perspectivas dos trabalhadores de saúde. Interface Comunicação, Saúde, Educação, Rio de janeiro, v.14, n. 32, p. 127-38, jan./mar. 2010. Disponível em: <http://www.scielo.br/scielo.php?pid=S1414-

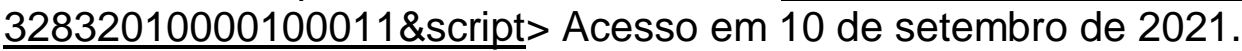

BRASIL. Ministério da Saúde. Secretaria de Atenção à Saúde. Departamento de Ações Programáticas Estratégicas. Saúde Mental no SUS: Os Centros de Atenção Psicossocial. Série F: Comunicação e Educação em Saúde. 1 ${ }^{a}$ Ed, Brasília, Distrito Federal, 86p. 2004. Disponível em: 
$<$ http://www.ccs.saude.gov.br/saude mental/pdf/SM Sus.pdf> Acesso em 07 de setembro de 2021.

DEMO, P. Metodologia Para Quem Quer Aprender. São Paulo: Atlas, 2008.

GIL, A. C. Como Elaborar Projetos de Pesquisa. 4. Ed., São Paulo: Atlas, 2002.

HEBERLE, A. Y.; OLIVEIRA, L. Grupos terapêuticos em saúde mental: Uma modalidade na prática dos serviços de atenção à saúde mental. Trabalho de Conclusão de Especialização em Saúde Coletiva: Estratégia Saúde da Família, Joaçaba, UNOESC, 2016.

MENEZES, Silveira de et al. Grupo de adolescentes em serviços de saúde mental: uma ferramenta de reabilitação psicossocial. Vínculo-Revista do NESME, v. 17, n. 2, p. 118-140, 2020. Disponível em: < https://www.redalyc.org/journal/1394/139465538006/html/> Acesso em 07 de setembro de 2021.

MINAYO, M. C. S.; COSTA, A. P. Fundamentos Teóricos das Técnicas de Investigação Qualitativa. Revista Lusófona de Educação, n. 40, p. 139-153, 2018. Disponível <https://revistas.ulusofona.pt/index.php/rleducacao/article/view/6439>. Acesso em 07 de setembro de 2021.

OTENIO, C. C. M.; NAKAMA, L.; LEFÈVRE, A. M. C.; LEFÈVRE, F. Trabalho multiprofissional: representações em um serviço público de saúde municipal. Saúde Social, São Paulo, v. 17, n. 4, p. 135-150, 2008. Disponível em: < https://www.scielo.br/j/sausoc/a/HfDT6wMvTHcBRW7GSvRh5Nz/abstract/?lang=pt> Acesso em 10 de setembro de 2021.

PICCIN, J; GRAEFF-MARTINS; A. S, ISOLAN; L, KIELING, C. (2019). Focos da atenção na adolescência. IN CORDIOLI, A. V.; GREVET, E. H. (Org.). Psicoterapias: abordagens atuais (4a ed., p. 347-362). Porto Alegre: Artmed, 2019.

SCHRANK, G.; OLSCHOWSKY, A. O Centro de Atenção Psicossocial e as estratégias para inserção da família. Revista Esc. Enfermagem - USP, São Paulo, v. 42, n. 1, mar. 2008. Disponível em: <http://www.lume.ufrgs.br/handle/10183/69671> Acesso em 10 de setembro de 2021.

SILVA, I. Z. Q. J.; TRAD, L. A. B. O trabalho em equipe no PSF: investigando a articulação técnica e a interação entre os profissionais. Interface - Comunicação, Saúde, Educ., v. 9, n. 16, p. 25-38, 2005. Disponível em:< https://www.scielo.br/i/icse/a/VCGLPDfFmn6cBSKDrvXbdfd/abstract/?lang=pt> Acesso em 10 de setembro de 2021. 